\title{
The Challenge of Polysubstance Use Overdose
}

\author{
Joseph V. Pergolizzi Jr.1,2,3, Giustino Varrassi' ${ }^{4}$, Jo Ann LeQuang1, Robert B. Raffa ${ }^{2,3,5,6}$ \\ ${ }^{1}$ NEMA Research Inc., Naples, FL, USA \\ ${ }^{2}$ Neumentum Inc., Summit, NJ, USA \\ ${ }^{3}$ Enalare Therapeutics Inc., Princeton, NJ, USA \\ ${ }^{4}$ Paolo Procacci Foundation, Roma, Italy \\ ${ }^{5}$ College of Pharmacy (Adjunct), University of Arizona, Tucson, AZ, USA \\ ${ }^{6}$ Temple University School of Pharmacy (Prof. Emer.), Philadelphia, PA, USA \\ Email: robert.raffa@temple.edu
}

How to cite this paper: Pergolizzi Jr., J. V., Varrassi, G., LeQuang, J. A., \& Raffa, R. B. (2021). The Challenge of Polysubstance Use Overdose. Open Journal of Social Sciences, 9, 529-542.

https://doi.org/10.4236/jss.2021.97038

Received: June 29, 2021

Accepted: July 27, 2021

Published: July 30, 2021

Copyright $\odot 2021$ by author(s) and Scientific Research Publishing Inc. This work is licensed under the Creative Commons Attribution International License (CC BY 4.0).

http://creativecommons.org/licenses/by/4.0/ (c) (i) Open Access

\begin{abstract}
Despite the urgency of the public health crisis of opioid overdose morbidity and mortality, and the widespread intense attention and effort directed toward its elimination, or at least its mitigation, deaths due to drug overdose are on the rise, and in fact are reaching all-time record highs. Fentanyl (real or counterfeit) and its legal and illicit analogs are certainly a major contributor to the problem, but another important driver is the significant increase in polysubstance abuse, which now occurs in the majority of overdose deaths. Polysubstance overdose presents a particular treatment challenge. Overdose victims might not be able to state what drugs they have taken, and if the products were adulterated, they themselves might not even know. Mechanistically, the resultant additive, or even synergistic, interaction between drugs adds a level of complexity above the standard treatment of using a mono-mechanistic receptor antagonist. We review these challenges.
\end{abstract}

\section{Keywords}

Opioid Crisis, Overdose, Drug Abuse, Polysubstance Use, Naloxone

\section{Introduction}

There remain misunderstandings about polysubstance use overdose. One misconception dating back to the pre-fentanyl era maintained that overdose deaths were the result of taking too much heroin. In reality, many overdoses were, and continue to be, more likely caused by what has been described as "heroin underdoses", in which the deaths are caused by the contribution of other drugs (Darke, Hall, Weatherburn, \& Lind, 1999; Monforte, 1977; Ruttenber, Kalter, \& 
Santinga, 1990; Ruttenber \& Luke, 1984). In other words, people who use heroin alone are not at as much risk of overdose as people who took heroin in combination with other substances. This was documented in a large-scale study of New York drug overdose deaths, in which it was found that variations in mortality rates were not due to differences among the various single substances, but rather were the result of polydrug use (Coffin et al., 2003). These and other studies reveal that polysubstance use disorder (PSUD) must be recognized as a major contributor to the public health crisis of overdose toxicity. The recent emergence of super-potent fentanyl and fentanyl analogs (F/FAs) has further exacerbated overdose mortality rates, whether taken unknowingly in street drugs or whether as part of a polysubstance cocktail.

Another important misunderstanding about overdose toxicity is that the opioid use disorder (OUD) population is relatively homogenous. While it is reasonably well understood that OUD does not respect demographic boundaries of age, race, ethnic group, sex, socioeconomic status, geographical location, or other such factors, less is appreciated about patterns of substance use disorder and the intersection of OUD and PSUD. People with any type of substance use disorder are sometimes relatively consistent in their preferences and use one substance exclusively, with little interest in variation or supplementation. At the other end of the spectrum are individuals who regularly, and by choice, use a variety of drugs, sometimes with specific preferred combinations, sometimes more randomly or opportunistically (Bunting, Oser, Staton, \& Knudsen, 2020; Bunting, Oser, Staton, \& Knudsen, 2021).

\section{Polysubstance Use Disorder (PSUD)}

PSUD can involve taking more than one substance at the same time, or it may describe the consecutive use of different substances. PSUD is not rare. In fact, most people who seek treatment for OUD actually are better described as having PSUD. PSUD is associated with a higher burden to the healthcare system than OUD and may exacerbate the rescue of individuals suffering respiratory depression (Manhapra \& Rosenheck, 2021). By far, the most severe consequence of PSUD may be the contribution to overdose deaths (Darke, 2003). While the increase in opioid mortality is often attributed to F/FAs, which indeed are a driver of the marked increase in overdose deaths (CDC, 2020), some of this increase is likely also due to PSUD.

Although polysubstance use lacks a formal precise definition, and is not well studied in terms of use patterns or motivations, the term generally refers to people who use substances simultaneously or sequentially or in a pattern known as "regular intervals" where the person takes more than one substance in the course of a day, week, or month (Bunting et al., 2021). Polysubstance use may be a marker for more severe and/or more complex forms of substance use disorder (Walker, Logan, Chipley, \& Miller, 2018). PSUD may involve more than just two substances or one route of administration. For example, in a study of 884 street 
drug users in Scandinavia in 2013 who reported using illegal substances within four weeks prior to inclusion, the average number of drugs used (all routes of administration) was nearly six, and more than half reported alcohol consumption in addition (Gjersing \& Bretteville-Jensen, 2018). Participants in this study were long-term users who reported injecting drugs for an average of $20.9 \pm 11.4$ years. The mean number of substances injected at one time was $2.04 \pm 1.10$, but if all routes of administration were considered it was $5.65 \pm 2.06$. The most frequently consumed drugs were prescription opioids, both intravenous (IV) and non-IV injection (85\%), prescription opioids taken by routes other than injection $(84 \%)$, cannabis $(82 \%)$, and amphetamine injection (60\%). Eighty percent of study participants reported ever injecting two or more substances simultaneously. The men and women in this study had an 11-and 26-fold greater increased risk of mortality, respectively, compared to the general population, with the most frequently reported cause of death being drug(s) overdose. Mortality predictors in this study included polysubstance injection and low frequency of injections (Gjersing \& Bretteville-Jensen, 2018).

In a study of residents $(\mathrm{n}=1674)$ at multiple long-term drug treatment programs in one U.S. state more than half $(n=896)$ self-reported having used an opioid in the past six months (Walker et al., 2018). While taking buprenorphine-naloxone as part of their recovery program, 70\% reported they took other drugs and/or drank alcohol concurrently. The other drugs were reported to be marijuana, benzodiazepines, cocaine, stimulants, hallucinogens, synthetic substances, and alcohol (Walker et al., 2018).

A study of 298 "persons who inject drugs" (PWID) in Baltimore, Maryland was conducted to determine patterns of substance use (Schneider, Park, Allen, Weir, \& Sherman, 2019). The study could place PWIDs into three broad categories: $40.2 \%$ injected both cocaine and heroin; $32.2 \%$ injected only heroin; and $27.6 \%$ used multiple drugs by multiple routes of administration. Opioids were used by all three groups. Users of heroin/cocaine were significantly more likely to be trained to use naloxone $(p=0.02)$ than were the other two groups $(76.5 \%$ of heroin/cocaine compared to $63 \%$ of heroin only and $60.3 \%$ of multiple drugs). The multiple-drug group was the least likely to have naloxone in their possession (37.2\%) (Schneider et al., 2019). In this cohort, 14\% had overdosed in the past 30 days, and the multiple-drug group had the highest rate of overdoses overall $(22.5 \%)$ in the past month. The heroin-only group had a 30-day overdose rate of $4.6 \%$ (Schneider et al., 2019). It should be noted that this study was conducted before the era of widespread fentanyl, which has complicated the study of overdose morbidity and mortality.

Thus, polysubstance users may be considered an important and unique subpopulation of people with OUD. They have a higher prevalence of overdose and they are less likely than other drug users to have or be instructed in the use of naloxone (Schneider et al., 2019). Furthermore, people with PSUD have a higher rate of homelessness and may be under more social, familial, and economic stress than do other groups of opioid users (Schneider et al., 2019). 
In a study of 398 drug-induced deaths in Spain during 2010 to 2011, 87\% were men and the mean age was 39.7 years. Two or more substances were identified in $86.7 \%$ of deaths; the most frequently observed substances were some combination of opioids, benzo-diazepines, cocaine, and alcohol (Fernández-Calderón et al., 2017). Most deaths (72\%) occurred in a residence, $11 \%$ occurred in the street, and $8 \%$ in prison. Suicide was suspected in 10\% (Fernández-Calderón et al., 2017). In a study of 6569 individuals with OUD who reported polysubstance use (which was defined as more than one substance per day), drug use patterns for 30 days before incarceration were evaluated and six distinct use profiles emerged (Table 1) (Bunting et al., 2021).

Amore general population with substance use disorder has also been studied using emergency room data to provide a demographic portrait. This involved a latent class analysis based on national syndromic surveillance of 120,706 suspected overdoses that occurred in 2017 to 2018 in the United States (Liu \& Vivolo-Kantor, 2020). This study highlighted that heroin and polysubstance use (which often involved heroin) presented a considerable burden to the healthcare system (Table 2).

Data from a national survey conducted in 2018 of 15,741 people entering treatment for OUD at multiple centers were compared to historical data from 2011 (Cicero, Ellis, \& Kasper, 2020). The use of an opioid in the past 30 days increased from $44.8 \%$ in 2011 to $70.1 \%$ in 2018, and the use of opioids alone (without other substances) dropped from 55.2\% in 2011 to $29.9 \%$ in 2018. More than $90 \%$ of the survey respondents from 2018 had consumed at least one additional drug in the past 30 days (Cicero et al., 2020). These investigators concluded that polysubstance use was the norm rather than the exception among

Table 1. Use patterns that emerged in a study of pre-incarceration polydrug use (Bunting et al., 2021).

\begin{tabular}{|c|c|c|}
\hline Profile & Substances & $\begin{array}{c}\text { Profile } \\
\text { prevalence }\end{array}$ \\
\hline $\begin{array}{c}1 \\
\text { Primarily alcohol }\end{array}$ & $\begin{array}{l}\text { Near daily use of alcohol plus marijuana and/or nonmedical } \\
\text { use of prescription opioids used about } 50 \% \text { of the time }\end{array}$ & $9.4 \%$ \\
\hline $\begin{array}{c}2 \\
\text { Primarily heroin }\end{array}$ & $\begin{array}{l}\text { Near daily use of heroin plus marijuana and/or nonmedical } \\
\text { use of prescription opioids used about } 40 \% \text { of the time }\end{array}$ & $19.0 \%$ \\
\hline $\begin{array}{l}3 \\
\text { Less PSU }\end{array}$ & $\begin{array}{l}\text { No single drug was used more than } 15 \text { days per month; } \\
\text { marijuana and nonmedical use of prescription opioids } \\
\text { was frequent }\end{array}$ & $34.3 \%$ \\
\hline $\begin{array}{c}4 \\
\text { Tranquilizers }\end{array}$ & $\begin{array}{l}\text { Near daily use of tranquilizers plus frequent nonmedical use } \\
\text { of prescription opioids; marijuana and/or amphetamines } \\
\text { were used } 30 \% \text { to } 40 \% \text { of the month }\end{array}$ & $16.3 \%$ \\
\hline $\begin{array}{l}5 \\
\text { Buprenorphine }\end{array}$ & $\begin{array}{l}\text { Near daily use of buprenorphine plus use of marijuana, } \\
\text { nonmedical use of prescription opioids and/or amphetamines } \\
\text { used about } 40 \% \text { of the month }\end{array}$ & $7.8 \%$ \\
\hline $\begin{array}{c}6 \\
\text { Stimulant-opioid }\end{array}$ & $\begin{array}{l}\text { Near daily use of cocaine with marijuana, heroin, and/or } \\
\text { nonmedical use of prescription opioids about } \\
50 \% \text { to } 60 \% \text { of the month }\end{array}$ & $13.2 \%$ \\
\hline
\end{tabular}


Table 2. A latent class analysis study based on national surveillance of overdose patients presenting to emergency rooms 2017-2018 (Liu \& Vivolo-Kantor, 2020).

\begin{tabular}{|c|c|c|}
\hline Class & Demographics & $\begin{array}{l}\text { Proportion of } \\
\text { Total ED visits }\end{array}$ \\
\hline $\begin{array}{l}\text { Mostly heroin } \\
\text { overdose }\end{array}$ & $68 \%$ men; $39 \%$ between ages of $25-34$ years & $42.5 \%$ \\
\hline $\begin{array}{l}\text { Overdose of an opioid } \\
\text { other than heroin }\end{array}$ & $60 \%$ men; $28.5 \%$ over age 55 & $27.3 \%$ \\
\hline Polysubstance use & $68 \%$ men & $11.0 \%$ \\
\hline $\begin{array}{c}\text { Nonopioids } \\
\text { (antidepressants) }\end{array}$ & $56 \%$ women & $10.5 \%$ \\
\hline Benzodiazepines & $58 \%$ women; $29 \%$ over age 55 & $8.0 \%$ \\
\hline
\end{tabular}

those with OUD (Cicero et al., 2020). In fact, among survey respondents in 2018 who used prescription opioids nonmedically and/or heroin or F/FAs, most took an average of four other nonopioid drugs and more than one type of opioid (Cicero et al., 2020).

A number of studies have been conducted by analyzing the syringes used by those who injected drugs, with the goal of identifying the residual substances in the syringe and using them as an indicator of drug use patterns. Syringes are mainly collected at rehabilitation centers or publicly supported harm-reduction stations where people are legally permitted to inject drugs. As an example of the results, in the European Syringe Collection and Analysis Project Enterprise (ESCAPE) study, 2664 used syringes gathered in 2017 and 2018 from several large European cities were evaluated using gas chromatography and ultra-high-performance liquid chromatographic analysis with mass spectrometry. The most frequently detected substances in this study were cocaine, heroin, buprenorphine, amphetamines, and synthetic cathinones ("khat") (Brunt et al., 2021).

In summary, PSUD represents an evolving and increasing big threat in the public health crisis of opioid use. PSUD is associated with worse outcomes, higher mortality (3-fold higher than single-substance use), poorer treatment retention, and higher rates of relapse (de la Fuente et al., 2014; Staiger, Richardson, Long, Carr, \& Marlatt, 2013; Williamson, Darke, Ross, \& Teesson, 2006). PSUD is further associated with greater unmet physical and mental health needs, increased risk-taking behaviors, increased rates of violence, and increased risk of overdose compared to those who have single-substance use disorder (Gilmore et al., 2018; Lorvick, Browne, Lambdin, \& Comfort, 2018; Pennings, Leccese, \& Wolff, 2002).

\section{The Role of Naloxone in PSUD Overdose}

Naloxone is more widely available now as a reversal agent for opioid toxicity than at any previous time in history. There have even been major efforts to expand community naloxone to help "bystanders" rescue overdoses, naloxone dis- 
tribution via pharmacies, and naloxone kits provided to first responders and other emergency personnel. People who use opioids medically or recreationally increasingly have the option to be trained in the use of naloxone and obtain naloxone kits. Yet despite these efforts to get more naloxone to people who take opioids or to those who are around those who take opioids, overdose rates continue to climb. This leads to the question as to whether or not these naloxone outreaches are working.

Naloxone has a long history as a safe and effective reversal agent for opioid overdose. It works by competitive displacement of the opioid from opioid receptors, and blocking the receptors; in that way, it helps to revive people at risk for potentially life-threatening opioid-induced respiratory depression. At standard doses, for example $1 \mathrm{mg} / \mathrm{kg}$ of IV naloxone, naloxone is considered safe even for opioid-naïve patients (Posner \& Burke, 1985). Naloxone has been deemed so valuable that community-based programs have been developed to provide first responders, emergency departments, paramedics, police, and even laypeople with easy-to-administer naloxone kits (Gunn et al., 2018). An autoinjector is available for use by laypeople (Raffa et al., 2017). But even as naloxone distribution and community use has expanded aggressively, drug-related deaths continue to increase (Fairbairn, Coffin, \& Walley, 2017).

Naloxone dosing has always been empirical and the optimal dose remains the subject of some debate (Connors \& Nelson, 2016). Even among experts, the dose range considered appropriate for naloxone varies widely. In a literature study about naloxone doses recommended by various specialty societies, $48 \%$ recommended starting IV naloxone at a dose of $0.05 \mathrm{mg}$ or less, while $36 \%$ recommended starting at $0.5 \mathrm{mg}$ IV or higher. It is not clear if the naloxone dose should be based on patient characteristics (opioid tolerance, respiration, etc.) or universally started at a particular dose and increased stepwise until reversal occurs. There is no consensus as to the maximum dose of naloxone or, indeed, if there is a dose limit. And incremental dosing is required, it is not clear as to when it should be stopped if the patient does not respond. Sources that specify a maximum dose vary from $0.2 \mathrm{mg}$ IV naloxone as an upper bound while others have stated $10 \mathrm{mg}$ IV naloxone or more may be reasonable in some cases (Connors \& Nelson, 2016).

The dosing of community naloxone is set by the "naloxone kit" and dose titration in this setting is not as practical. Prior to the entry of F/FAs into the illicit drug supply and recognition of widespread PSUD, there was little experience with high doses of naloxone. Clinically important changes in systolic blood pressure and respiratory rate with no corresponding change in pulse rate have been observed to occur in healthy adults administered doses of 2 to $4 \mathrm{mg} / \mathrm{kg}$ IV naloxone (Cohen, Cohen, Pickar, Murphy, \& Bunney, 1982). While it is recommended to use the lowest effective dose of naloxone, in emergency situations with potentially negative outcomes, higher doses are often administered (Rzasa Lynn \& Galinkin, 2018). There are reports of side effects associated with high-dose naloxone use, including pulmonary edema, cardiac arrhythmias, hypertension, 
hypotension, and cardiac arrest, although these complications are not often fatal (Rzasa Lynn \& Galinkin, 2018). However, the use of naloxone has been shown to increase heart rate, cardiac output and arterial blood pressure (Huse, Hartung, \& Nadjmabadi, 1974). People with underlying arrhythmias may be at particular risk for naloxone-induced arrhythmias (Rzasa Lynn \& Galinkin, 2018), and the literature reports cardiac arrest in an otherwise healthy person administered 0.2 mg IV naloxone (Andree, 1980).

Naloxone precipitates abrupt opioid withdrawal, which frequently results in patient agitation and confusion along with classic withdrawal symptoms. A person with suspected opioid-induced respiratory depression who has also taken cocaine may be rescued with nalox-one and suddenly emerge in opioid withdrawal in a hyperactive, intoxicated, and possibly combative state while still under the full effects of cocaine (Rzasa Lynn \& Galinkin, 2018).

Many studies about overdose rescue do not record the doses of naloxone used. In general, the literature recommends incremental dosing of naloxone, starting at a low dose and ramping up as needed after short waits, but it is not clear whether such caution is warranted when dealing with a life-threatening medical emergency (Rzasa Lynn \& Galinkin, 2018). In addition, PSUD may make patients less responsive to naloxone rescue. In patients treated for overdose at emergency departments, polysubstance users were significantly more likely to receive multiple doses of naloxone $(p<0.01)$ (Heaton, Bhandari, Faryar, \& Huecker, 2019).

\section{Is PSUD Changing What We Know about Drug-Related Morbidity and Mortality?}

PSUD has long been a known general concept. For example, it is known that cigarette smokers are more likely to consume alcohol than are non-smokers; and regular users of marijuana are more likely to use opioids recreationally than are those who never use marijuana. These patterns persist across different substances, genders, age groups, locations, and social strata (Han, Compton, Blanco, \& DuPont, 2017). Among PWID, PSUD is increasingly the norm (Calabria et al., 2010). PSUD can complicate treatment, increase the risk for toxicity, and it may make rescue more difficult in the event of overdose (Betts et al., 2016).

PSUD results for a number of reasons. Sometimes multiple substances are taken by recreational users in order to enhance the effect of the main substance, such as opioid users who simultaneously take benzodiazepines (Han, Compton, Blanco, \& Jones, 2018). In other cases, combinations of drugs may be taken to balance out the individual drug effects. For instance, cocaine and heroin may be combined because heroin helps "smooth out" the rough crash that users may experience when the short-lived cocaine effects wear off (Compton, Valentino, \& DuPont, 2021). Some individuals experiment with combinations just to see what they are like. Others use multiple substances opportunistically, taking whatever drugs are most readily available and/or most affordable. An unfortunate consequence is that people experiencing suspected drug-induced respiratory depres- 
sion are particularly challenging to treat because they likely arrive in emergency medical care unresponsive and it is not possible to know with certainty what drugs they have taken. In some cases, as with fentanyl-laced heroin masked as heroin, even the user may not be aware of the drugs used. Thus, the standard approach of using naloxone to treat opioid overdose is not always immediately effective because the person suffering respiratory depression may or may not have used an opioid, or have symptoms caused by some other drug or drug combination.

Drug combinations may have additive effects or synergistic effects (effects greater than the sum of the parts), and the additive or synergistic effects may be positive or negative. Toxicity can also be enhanced by pharmacokinetic and/or pharmacodynamic drug-drug interactions (Shah, Lathrop, Reichard, \& Landen, 2008). Opioids combined with sedatives or central nervous system depressants (benzodiazepines, alcohol, among others) are particularly dangerous and may increase the risk for potentially lethal respiratory depression (Jones \& McAninch, 2015). Unfortunately, it is unlikely that people with PSUD have a full appreciation of pharmacologic drug-drug interactions.

\section{Non-Fatal Overdoses}

Just as polydrug users are not a monolithic group, not all overdoses are the same. They may of course be described in binary fashion as non-fatal or fatal, but also on a continuum with various degrees of severity and morbidity. Non-fatal overdoses are not well studied (Darke, Mattick, \& Degenhardt, 2003; Kerr et al., 2006) and are likely under-reported, because spontaneous recovery or resuscitation by a bystander without medical intervention may obviate the need to report to a medical facility. Complications associated with non-fatal overdose can be substantial: hypoxic brain injury, rhabdomyolysis, renal failure, and aspiration pneumonia (Darke et al., 2003). What little is known about non-fatal overdoses centers on opioid overdose rather than polysubstance overdose, although certainly people with PSUD are involved in non-fatal overdoses (Darke et al., 2003). In a study in Vancouver that recruited 1587 participants (median age at baseline 33.4 years, $64 \%$ men), which contributed a total of 12,030 observations during the course of the study, upon entry into the study, $47 \%(\mathrm{n}=750)$ stated that they had a non-fatal overdose previously. During the study period, 519 (33\%) of participants reported a total of 985 non-fatal overdoses (Kerr et al., 2006). Polysubstance-related factors associated with non-fatal overdose include "speedball" injection (cocaine/heroin), morphine injection, use of benzodiazepines, and binge drinking; other factors may play a role as well, such as homelessness, younger age, recent incarceration, needing help to inject drugs, and having been denied treatment for addiction (Kerr et al., 2006).

Emergency department data show that in that in 2017, there were 967,615 non-fatal overdoses treated in the United States, an increase over the prior year for every type of drug except benzodiazepines (which decreased 5.2\%) (Vivolo-Kantor et al., 2020). Cocaine overdose rates increased $32.9 \%$ and a study from 
2016 reported that of nonfatal drug overdoses involving cocaine, $27 \%$ also involved an opioid (Hoots, Vivolo-Kantor, \& Seth, 2020). The use of amphetamines in polydrug overdoses also increased from 2018 to 2019 (Liu, Scholl, Hoots, \& Seth, 2020). In fact, there has been an increase in polydrug overdoses nationwide since 2016 (Liu et al., 2020). In this connection, non-fatal overdose is a key risk factor for an eventual fatal drug overdose (Caudarella et al., 2016).

\section{PSUD Mortality}

In 2017, there were 70,237 overdose deaths in the United States, of which 47,600 (about two-thirds) involved at least one opioid (Wilson, Kariisa, Seth, Smith, \& Davis, 2020). During this time, F/FAs changed the landscape of American street drug use and F/FAs continue to be part of polysubstance use (DEA, 2018). F/FAs are relatively cheap, readily available, often mixed with other drugs, highly potent, and considered to be a driver behind currently high levels of opioid overdose fatalities (CDC, 2018). In 2016, 80\% of overdose deaths in the United States involving an F/FA also involved other substance(s), most frequently cocaine, benzodiazepines, alcohol, antidepressants, psychostimulants, or other opioids (Jones, Einstein, \& Compton, 2018). In some cases, polysubstance use involving F/FAs is intentional and volitional, but in other cases, drug dealers may not disclose that they are selling adulterated product, such as fentanyl-laced heroin (Carroll, Marshall, Rich, \& Green, 2017). Of increased concern, is that the use of F/FAs may expose the user to "wooden chest syndrome" (WCS) a little-appreciated form of paroxysmal chest wall rigidity that can become lethal in a matter of minutes (Burns, DeRienz, Baker, Casavant, \& Spiller, 2016). Naloxone may be less effective in reversing WCS (Levine, Veliz, \& Singer, 2020; Torralva \& Janowsky, 2019). F/FAs are highly lipophilic substances that enter the brain rapidly and although they are opioids, they may not respond as well to naloxone competition (Peppin, Pergolizzi Jr., Dahan, \& Raffa, 2021). This also applies to other reversal agents such as nalmefene and naltrexone, which may reduce opioid-induced respiratory depression (Peppin et al., 2021). As PSUD and F/FA use have both increased and often go together, naloxone may no longer be as effective a reversal agent. While a single dose was once thought to be reliable for reversing opioid-induced respiratory depression (Moss et al., 2020), by 2017 over $80 \%$ of those treated with naloxone for suspected opioid overdose required more than one dose before there was a response (Somerville et al., 2017).

Data regarding overdose mortality are not always rigorously collected, resulting in a relative paucity of data about polysubstance mortality even when such deaths occur in an observed setting. Further, when post-mortem evaluations of polysubstance overdose deaths are not able to pinpoint the drug that is the actual cause of death, such deaths are often described with such unhelpful terms as "mixed drug intoxication" (Davis, 2014).

\section{Future Directions}

Suspected opioid overdose must be treated as a medical emergency, but the role 
of naloxone, once a reliable resuscitator, is increasingly challenged with the increasing incidence of polysubstance abuse combined with F/FAs, and the fact that treatment often must be initiated without knowing which substances were involved. For that reason, treatment that would be "agnostic" as to the cause of the respiratory depression could be an evolving medical need.

\section{Conclusion}

Overdose morbidity and mortality continue to escalate despite the widespread use and community-based initiatives for naloxone rescue. Changes in the drug landscape, particularly the entry of F/FAs into the street drug market combined with the more widespread pattern of PSUD, threaten to make opioid antagonists less reliable at reversing suspected drug-related respiratory depression. There is no consensus as to appropriate naloxone dosing and highly potent lipophilic synthetic opioids such as F/FAs may require very large doses of naloxone or may incompletely respond to naloxone due to WCS. While naloxone remains a valuable agent for opioid reversal, the role of single-mechanism reversal agents in the public health crisis of overdose morbidity and mortality seems increasingly beset with questions. More attention should be paid to studying the psycho-social causes of polysubstance use, and to the challenges of treating polysubstance overdose.

\section{Conflicts of Interest}

The authors declare no conflicts of interest regarding the publication of this paper.

\section{References}

Andree, R. A. (1980). Sudden Death Following Naloxone Administration. Anesthesia \& Analgesia, 59, 782-784. https://doi.org/10.1213/00000539-198010000-00012

Betts, K. S., Chan, G., Mcllwraith, F., Dietze, P., Whittaker, E., Burns, L., \& Alati, R. (2016). Differences in Polysubstance Use Patterns and Drug-Related Outcomes between People Who Inject Drugs Receiving and Not Receiving Opioid Substitution Therapies. Addiction (Abingdon, England), 111, 1214-1223.

https://doi.org/10.1111/add.13339

Brunt, T. M., Lefrançois, E., Gunnar, T., Arponen, A., Seyler, T., Goudriaan, A. E., \& Nefau, T. (2021). Substances Detected in Used Syringes of Injecting Drug Users across 7 Cities in Europe in 2017 and 2018: The European Syringe Collection and Analysis Project Enterprise (ESCAPE). International Journal of Drug Policy, Article ID: 103130. https://doi.org/10.1016/j.drugpo.2021.103130

Bunting, A. M., Oser, C. B., Staton, M., \& Knudsen, H. K. (2021). Pre-Incarceration Polysubstance Use Involving Opioids: A Unique Risk Factor of Postrelease Return to Substance Use. Journal of Substance Abuse Treatment, 127, Article ID: 108354. https://doi.org/10.1016/j.jsat.2021.108354

Bunting, A. M., Oser, C., Staton, M., \& Knudsen, H. (2020). Polysubstance Use Patterns among Justice-Involved Individuals Who Use Opioids. Substance Use and Misuse, 55, 2165-2174. https://doi.org/10.1080/10826084.2020.1795683 
Burns, G., DeRienz, R. T., Baker, D. D., Casavant, M., \& Spiller, H. A. (2016). Could Chest Wall Rigidity Be a Factor in Rapid Death from Illicit Fentanyl Abuse? Clinical Toxicology, 54, 420-423. https://doi.org/10.3109/15563650.2016.1157722

Calabria, B., Degenhardt, L., Briegleb, C., Vos, T., Hall, W., Lynskey, M., McLaren, J. et al. (2010). Systematic Review of Prospective Studies Investigating "Remission" from Amphetamine, Cannabis, Cocaine or Opioid Dependence. Addictive Behaviors, 35, 741-749. https://doi.org/10.1016/j.addbeh.2010.03.019

Carroll, J. J., Marshall, B. D. L., Rich, J. D., \& Green, T. C. (2017). Exposure to Fentanyl-Contaminated Heroin and Overdose Risk among Illicit Opioid Users in Rhode Island: A Mixed Methods Study. International Journal of Drug Policy, 46, 136-145. https://doi.org/10.1016/j.drugpo.2017.05.023

Caudarella, A., Dong, H., Milloy, M. J., Kerr, T., Wood, E., \& Hayashi, K. (2016). Non-Fatal Overdose as a Risk Factor for Subsequent Fatal Overdose among People Who Inject Drugs. Drug and Alcohol Dependence, 162, 51-55.

https://doi.org/10.1016/j.drugalcdep.2016.02.024

CDC (2018). Illicitly Made Fentanyl Use Is on the Rise. Opioid Overdose. https://www.cdc.gov/drugoverdose/opioids/fentanyl.html

CDC (2020). Synthetic Opioid Overdose. https://www.cdc.gov/drugoverdose/data/fentanyl.html

Cicero, T. J., Ellis, M. S., \& Kasper, Z. A. (2020). Polysubstance Use: A Broader Understanding of Substance Use during the Opioid Crisis. American Journal of Public Health, 110, 244-250. https://doi.org/10.2105/AJPH.2019.305412

Coffin, P. O., Galea, S., Ahern, J., Leon, A. C., Vlahov, D., \& Tardiff, K. (2003). Opiates, Cocaine and Alcohol Combinations in Accidental Drug Overdose Deaths in New York City, 1990-98. Addiction, 98, 739-747. https://doi.org/10.1046/j.1360-0443.2003.00376.x

Cohen, M. R., Cohen, R. M., Pickar, D., Murphy, D. L., \& Bunney, W. E. Jr. (1982). Physiological Effects of High Dose Naloxone Administration to Normal Adults. Life Sciences, 30, 2025-2031. https://doi.org/10.1016/0024-3205(82)90443-X

Compton, W. M., Valentino, R. J., \& DuPont, R. L. (2021). Polysubstance Use in the U.S. Opioid Crisis. Molecular Psychiatry, 26, 41-50. https://doi.org/10.1038/s41380-020-00949-3

Connors, N. J., \& Nelson, L. S. (2016). The Evolution of Recommended Naloxone Dosing for Opioid Overdose by Medical Specialty. Journal of Medical Toxicology, 12, 276-281. https://doi.org/10.1007/s13181-016-0559-3

Darke, S. (2003). Polydrug Use and Overdose: Overthrowing Old Myths. Addiction, 98, 711-711. https://doi.org/10.1046/j.1360-0443.2003.00416.x

Darke, S., Hall, W., Weatherburn, D., \& Lind, B. (1999). Fluctuations in Heroin Purity and the Incidence of Fatal Heroin Overdose. Drug and Alcohol Dependence, 54, 155-161. https://doi.org/10.1016/S0376-8716(98)00159-8

Darke, S., Mattick, R. P., \& Degenhardt, L. (2003). The Ratio of Non-Fatal to Fatal Heroin Overdose. Addiction, 98, 1169-1171. https://doi.org/10.1046/j.1360-0443.2003.00474.x

Davis, G. G. (2014). Complete Republication: National Association of Medical Examiners Position Paper: Recommendations for the Investigation, Diagnosis, and Certification of Deaths Related to Opioid Drugs. Journal of Medical Toxicology, 10, 100-106. https://doi.org/10.1007/s13181-013-0323-x

De la Fuente, L., Molist, G., Espelt, A., Barrio, G., Guitart, A., Bravo, M. J., \& Brugal, M. T. (2014). Mortality Risk Factors and Excess Mortality in a Cohort of Cocaine Users 
Admitted to Drug Treatment in Spain. Journal of Substance Abuse Treatment, 46, 219-226. https://doi.org/10.1016/j.jsat.2013.07.001

DEA (2018). Fentanyl Remains the Most Significant Synthetic Opioid Threat and Poses the Greatest Threat to the Opioid User Market in the United States. DEA-DCT-D1B-003-18. https://www.dea.gov/sites/default/files/2018-07/PRB-DIB-003-18.pdf

Fairbairn, N., Coffin, P. O., \& Walley, A. Y. (2017). Naloxone for Heroin, Prescription Opioid, and Illicitly Made Fentanyl Overdoses: Challenges and Innovations Responding to a Dynamic Epidemic. International Journal of Drug Policy, 46, 172-179. https://doi.org/10.1016/j.drugpo.2017.06.005

Fernández-Calderón, F., Blanco-Rodríguez, M., Martín-Cazorla, F., Martínez-Téllez, I., Soriano-Ramón, T., \& Bilbao-Acedos, I. (2017). Drug-Induced Deaths in Southern Spain: Profiles and Associated Characteristics. Journal of Substance Use, 22, 289-294. https://doi.org/10.1080/14659891.2016.1190412

Gilmore, D., Zorland, J., Akin, J., Johnson, J. A., Emshoff, J. G., \& Kuperminc, G. P. (2018). Mortality Risk in a Sample of Emergency Department Patients Who Use Cocaine with Alcohol and/or Cannabis. Substance Abuse, 39, 266-270. https://doi.org/10.1080/08897077.2017.1389799

Gjersing, L., \& Bretteville-Jensen, A. L. (2018). Patterns of Substance Use and Mortality Risk in a Cohort of "Hard-to-Reach" Polysubstance Users. Addiction (Abingdon, England), 113, 729-739. https://doi.org/10.1111/add.14053

Gunn, A. H., Smothers, Z. P. W., Schramm-Sapyta, N., Freiermuth, C. E., MacEachern, M., \& Muzyk, A. J. (2018). The Emergency Department as an Opportunity for Naloxone Distribution. Western Journal of Emergency Medicine, 19, 1036-1042. https://doi.org/10.5811/westjem.2018.8.38829

Han, B., Compton, W. M., Blanco, C., \& DuPont, R. L. (2017). National Trends in Substance Use and Use Disorders among Youth. Journal of American Academy of Child and Adolescent Psychiatry, 56, 747-754.e743. https://doi.org/10.1016/j.jaac.2017.06.011

Han, B., Compton, W. M., Blanco, C., \& Jones, C. M. (2018). Correlates of Prescription Opioid Use, Misuse, Use Disorders, and Motivations for Misuse among US Adults. Journal of Clinical Psychiatry, 79, 17m11973. https://doi.org/10.4088/JCP.17m11973

Heaton, J. D., Bhandari, B., Faryar, K. A., \& Huecker, M. R. (2019). Retrospective Review of Need for Delayed Naloxone or Oxygen in Emergency Department Patients Receiving Naloxone for Heroin Reversal. Journal of Emergency Medicine, 56, 642-651. https://doi.org/10.1016/j.jemermed.2019.02.015

Hoots, B., Vivolo-Kantor, A., \& Seth, P. (2020). The Rise in Non-Fatal and Fatal Overdoses Involving Stimulants with and without Opioids in the United States. Addiction, 115, 946-958. https://doi.org/10.1111/add.14878

Huse, K., Hartung, E., \& Nadjmabadi, M. H. (1974). The Effects of Naloxone (Narcan) on Circulation and Respiration after Neurolept Anaesthesia for Neurosurgical Operations (Author's Transl). Anaesthesist, 23, 493-499.

Jones, C. M., \& McAninch, J. K. (2015). Emergency Department Visits and Overdose Deaths from Combined Use of Opioids and Benzodiazepines. American Journal of Preventive Medicine, 49, 493-501. https://doi.org/10.1016/j.amepre.2015.03.040

Jones, C. M., Einstein, E. B., \& Compton, W. M. (2018). Changes in Synthetic Opioid Involvement in Drug Overdose Deaths in the United States, 2010-2016. JAMA, 319, 1819-1821. https://doi.org/10.1001/jama.2018.2844

Kerr, T., Fairbairn, N., Tyndall, M., Marsh, D., Li, K., Montaner, J., \& Wood, E. (2006). 
Predictors of Non-Fatal Overdose among a Cohort of Polysubstance-Using Injection Drug Users. Drug and Alcohol Dependence, 87, 39-45.

https://doi.org/10.1016/j.drugalcdep.2006.07.009

Levine, R., Veliz, S., \& Singer, D. (2020). Wooden Chest Syndrome: Beware of Opioid Antagonists, Not Just Agonists. American Journal of Emergency Medicine, 38, 411.e415-411.e416. https://doi.org/10.1016/j.ajem.2019.09.009

Liu, S., \& Vivolo-Kantor, A. (2020). A Latent Class Analysis of Drug and Substance Use Patterns among Patients Treated in Emergency Departments for Suspected Drug Overdose. Addictive Behaviors, 101, Article ID: 106142.

https://doi.org/10.1016/j.addbeh.2019.106142

Liu, S., Scholl, L., Hoots, B., \& Seth, P. (2020). Nonfatal Drug and Polydrug Overdoses Treated in Emergency Departments-29 States, 2018-2019. MMWR Morbitity and Mortality Weekly Report, 69, 1149-1155. https://doi.org/10.15585/mmwr.mm6934a1

Lorvick, J., Browne, E. N., Lambdin, B. H., \& Comfort, M. (2018). Polydrug Use Patterns, Risk Behavior and Unmet Healthcare Need in a Community-Based Sample of Women Who Use Cocaine, Heroin or Methamphetamine. Addictive Behaviors, 85, 94-99. https://doi.org/10.1016/j.addbeh.2018.05.013

Manhapra, A., \& Rosenheck, R. (2021). Commentary on Lin et al.: Saving Lives during the Opioid Crisis-Widening the Focus from Opioid Use Disorder to Polysubstance Use Disorder and to Multimorbidity. Addiction, 116, 105-106.

https://doi.org/10.1111/add.15229

Monforte, J. R. (1977). Some Observations Concerning Blood Morphine Concentrations in Narcotic Addicts. Journal of Forensic Science, 22, 718-724. https://doi.org/10.1520/JFS10410I

Moss, R. B., Pryor, M. M., Baillie, R., Kudrycki, K., Friedrich, C., Reed, M., \& Carlo, D. J. (2020). Higher Naloxone Dosing in a Quantitative Systems Pharmacology Model That Predicts Naloxone-Fentanyl Competition at the Opioid Mu Receptor Level. PLoS ONE, 15, e0234683. https://doi.org/10.1371/journal.pone.0234683

Pennings, E. J., Leccese, A. P., \& Wolff, F. A. (2002). Effects of Concurrent Use of Alcohol and Cocaine. Addiction, 97, 773-783. https://doi.org/10.1046/j.1360-0443.2002.00158.x

Peppin, J. F., Pergolizzi Jr, J. V., Dahan, A., \& Raffa, R. B. (2021). Are Opioid Receptor Antagonists Adequate for "Opioid" Overdose in a Changing Reality? Journal of Clinical Pharmacy and Therapeutics. (In Press) https://doi.org/10.1111/jcpt.13320

Posner, J., \& Burke, C. A. (1985). The Effects of Naloxone on Opiate and Placebo Analgesia in Healthy Volunteers. Psychopharmacology (Berlin), 87, 468-472. https://doi.org/10.1007/BF00432515

Raffa, R. B., Taylor, R., Jr., Pergolizzi, J. V. Jr., Nalamachu, S., Edwards, E. S., \& Edwards, E. T. (2017). Application of Human Factors Engineering (HFE) to the Design of a Naloxone Auto-Injector for the Treatment of Opioid Emergencies. Drug Delivery and Translational Research, 7, 1-10. https://doi.org/10.1007/s13346-016-0323-x

Ruttenber, A. J., \& Luke, J. L. (1984). Heroin-Related Deaths: New Epidemiologic Insights. Science, 226, 14-20. https://doi.org/10.1126/science.6474188

Ruttenber, A. J., Kalter, H. D., \& Santinga, P. (1990). The Role of Ethanol Abuse in the Etiology of Heroin-Related Death. Journal of Forensic Sciences, 35, 891-900. https://doi.org/10.1520/JFS12902J

Rzasa Lynn, R., \& Galinkin, J. L. (2018). Naloxone Dosage for Opioid Reversal: Current Evidence and Clinical Implications. Therapeutic Advances in Drug Safety, 9, 63-88. https://doi.org/10.1177/2042098617744161

Schneider, K. E., Park, J. N., Allen, S. T., Weir, B. W., \& Sherman, S. G. (2019). Patterns 
of Polysubstance Use and Overdose among People Who Inject Drugs in Baltimore, Maryland: A Latent Class Analysis. Drug and Alcohol Dependence, 201, 71-77. https://doi.org/10.1177/2042098617744161

Shah, N. G., Lathrop, S. L., Reichard, R. R., \& Landen, M. G. (2008). Unintentional Drug Overdose Death Trends in New Mexico, USA, 1990-2005: Combinations of Heroin, Cocaine, Prescription Opioids and Alcohol. Addiction, 103, 126-136.

https://doi.org/10.1111/j.1360-0443.2007.02054.x

Somerville, N. J., O’Donnell, J., Gladden, R. M., Zibbell, J. E., Green, T. C., Younkin, M., Walley, A. Y. et al. (2017). Characteristics of Fentanyl Overdose-Massachusetts, 2014-2016. MMWR Morbidity and Mortality Weekly Report, 66, 382-386.

https://doi.org/10.15585/mmwr.mm6614a2

Staiger, P. K., Richardson, B., Long, C. M., Carr, V., \& Marlatt, G. A. (2013). Overlooked and Underestimated? Problematic Alcohol Use in Clients Recovering from Drug Dependence. Addiction, 108, 1188-1193. https://doi.org/10.15585/mmwr.mm6614a2

Torralva, R., \& Janowsky, A. (2019). Noradrenergic Mechanisms in Fentanyl-Mediated Rapid Death Explain Failure of Naloxone in the Opioid Crisis. Journal of Pharmacology and Experimental Therapeutics, 371, 453-475.

https://doi.org/10.1124/jpet.119.258566

Vivolo-Kantor, A. M., Hoots, B. E., Scholl, L., Pickens, C., Roehler, D. R., Board, A., Liu, S. et al. (2020). Nonfatal Drug Overdoses Treated in Emergency Departments-United States, 2016-2017. MMWR Morbidity and Mortality Weekly Report, 69, 371-376. https://doi.org/10.15585/mmwr.mm6913a3

Walker, R., Logan, T. K., Chipley, Q. T., \& Miller, J. (2018). Characteristics and Experiences of Buprenorphine-Naloxone Use among Polysubstance Users. American Journal of Drug and Alcohol Abuse, 44, 595-603. https://doi.org/10.1080/00952990.2018.1461876

Williamson, A., Darke, S., Ross, J., \& Teesson, M. (2006). The Effect of Persistence of Cocaine Use on 12-Month Outcomes for the Treatment of Heroin Dependence. Drug and Alcohol Dependence, 81, 293-300. https://doi.org/10.1016/j.drugalcdep.2005.08.010

Wilson, N., Kariisa, M., Seth, P., Smith, H. T., \& Davis, N. L. (2020). Drug and Opioid-Involved Overdose Deaths-United States, 2017-2018. MMWR Morbidity and Mortality Weekly Report, 69, 290-297. https://doi.org/10.15585/mmwr.mm6911a4 